\title{
SELECTION OF BEST HOSPITAL FOR KIDNEY TRANSPLANTATION USING AHP: A CASE FOR TURKEY
}

\author{
Fatma Kutlu Gündoğdu ${ }^{1}$, Ali Karasan ${ }^{2}$ \\ ${ }^{1}$ National Defence University, Turkish Air Force Academy, Industrial Engineering Department, 34149, \\ Yeşilyurt, İstanbul \\ ${ }^{2}$ Yildiz Technical University, Department of Industrial Engineering, Besiktas Istanbul 34347, Turkey
}

\begin{abstract}
The assessment of service quality in a hospital for organ transplantation has been mainly ignored by health care suppliers, although it has vital importance for human life. In this study, service quality parameters are determined in the light of four SERVQUAL dimensions, including responsiveness, reliability, tangibles, and empathy, and a survey has been conducted. Twenty-one patients who are suffering from kidney failure and also their relatives have attended this survey. The analytic hierarchy process (AHP) is constructed to select the best hospital in Istanbul for kidney transplantation based on these service quality parameters, and results are discussed.
\end{abstract}

Keywords: AHP, decision-making, kidney exchange, Service Quality

\section{Introduction}

In Turkey, kidney transplantation assignments are performed by the National Coordination System (NCS). The database obtains organ and tissue donations, transplantations records, receivers, and donor information from hospitals. Patients have to wait for a long time because of some criteria such as shortage of donors, medical urgency, age, blood group, matching of specific tissue/blood characteristics, dialysis time obtained from the database. Currently, there are 72 kidney transplantation centers in Turkey. Turkey takes place in an excellent position in the number of transplants from living donors due to strong relative bonds. However, In Turkey, the number of patients whose treatment is only possible for a kidney transplant is increasing, and also this increment makes kidney transplantation more critical. There are roughly 22,981 kidney patients in Turkey registered on a central waiting list for transplantation from live or cadaver kidney based on a 2019 Health Ministry report. In this point, selection the best hospital for kidney surgery in terms of patients and their relatives, it has vital importance because all patients have one or less chance to get a healthy kidney (Url1).

Measuring healthcare service performance can be a complicated mission as it has multiple functions to achieve overall goals. Many complicated problems are successfully solved with the Analytical Hierarchy Process (AHP) method in health-care systems.

This study's scope concentrates on, for kidney transplantation, selecting the best hospital concerning the quality of health care service parameters compared with three hospitals in Istanbul.

\section{Literature Review}

Providing better hospital service quality is one of the significant concerns of the healthcare industry. Since health services in Turkey are provided in a very competitive environment, for making a better choice, the services delivered by the public and private hospitals should be evaluated according to the viewpoint of patients who suffers from organ failure. 
ISAHP Article: A Style Guide for Paper Proposals To Be Submitted to the International Symposium on the Analytic Hierarchy Process 2020, Web Conference.

Integrated SERVQUAL and AHP method is implemented to many service industries such as healthcare, transportation, education, and safety (Yucesan and Gul, 2020). Similar to this study, Aktas et al. (2015) considered a list of criteria gathered from the literature to classify the hospitals based on an MCDM methodology outcomes. In the current literature, there is still no attempt to evaluate service quality performance of health-care systems from the viewpoint patients and relatives who suffers from kidney failure. As differ from the literature, the study aims to decide best hospital for kidney transplantation from living donor to patient using AHP in terms of location of selected hospitals, quality of treatment, medical staff, information flow between staff and patients, success rate of transplantation, and selection of equipment for surgery of kidney etc. Therefore, this paper aims to fill the gap in this area implementing this approach.

\section{The Objective of the Study}

In this study, selection of best hospital for kidney transplantation by using AHP technique is considered for the hospitals in the city of Istanbul, Turkey. The assumption, no dependency between the criteria, is considered. Through that, a hierarchical structure is constructed for the solution of the problem.

\section{Analytical Hierarchy Process: Evaluation of Health-Care System}

The main goal is choosing the best hospital among three alternatives, such as Florence Nightingale, Memorial, and Medicana Şişli Hospitals, for kidney transplantation using the AHP method. For this method, four main service quality parameters and thirteen subcriteria were defined. The main criteria are that tangibles, reliability, responsiveness, and empathy. For example, the first main tangible criterion has four sub-criteria such as modern equipment, physical facilities, cleanliness, and value for money. All criteria and subcriteria were determined based on the Aktas et al. (2015) research.

According to the AHP structure is given in Fig.1, a survey is prepared to construct pairwise matrices. A total of 42 patients who wait for kidney transplantation and their relatives participated in this survey. For dealing with data, Super Decisions Software was used.

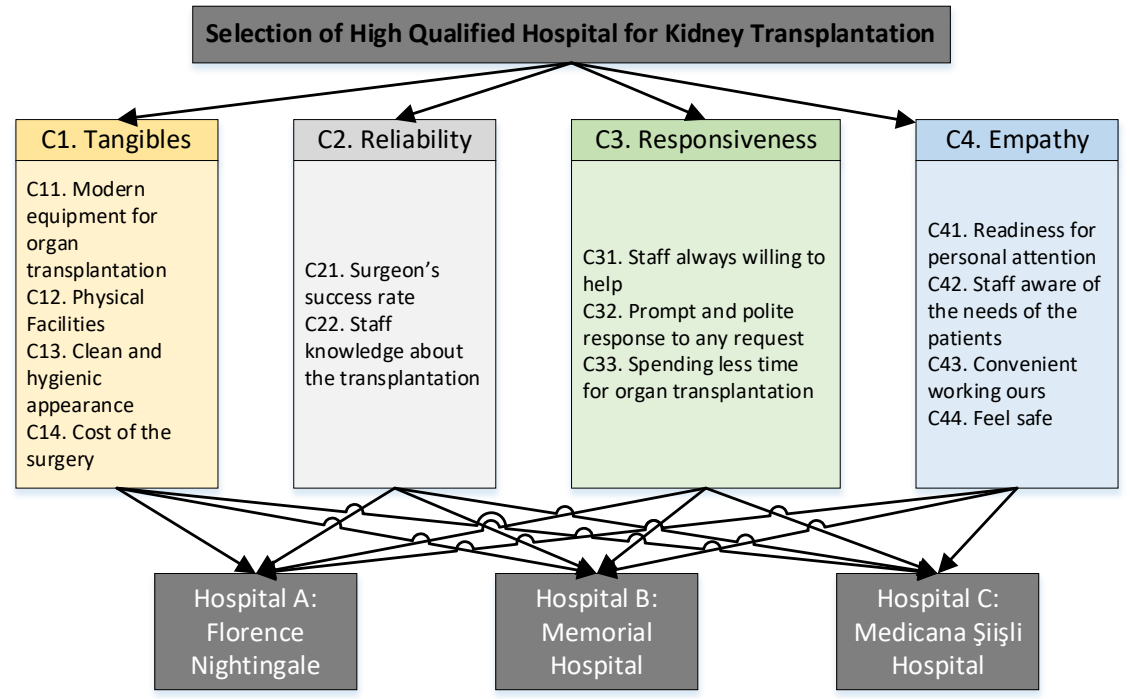

Figure 1. Structure of the method used for case study

\section{Data/Model Analysis}

International Symposium on the 
ISAHP Article: A Style Guide for Paper Proposals To Be Submitted to the International Symposium on the Analytic Hierarchy Process 2020, Web Conference.

Table 1 indicates the pairwise comparison matrix of the main criteria Due to the space constraints, the rest of the pairwise matrices are omitted.

Table 1: Pairwise comparison matrix of he main criteria

\begin{tabular}{|l|l|l|l|l|}
\hline Inconsistency & Tangibles & Reliability & Responsiveness & Empathy \\
\hline Tangibles & 1 & $1 / 1.58$ & 1.64 & 1.89 \\
\hline Reliability & 1.58 & 1 & 1.93 & 2.01 \\
\hline Responsiveness & $1 / 1.64$ & $1 / 1.93$ & 1 & 1.72 \\
\hline Empathy & $1 / 1.89$ & $1 / 2.01$ & $1 / 1.72$ & 1 \\
\hline
\end{tabular}

According to Table 2, the best hospital for kidney transplantation is Florence Nightingale Hospital in terms of service quality is about four dimensions: tangibles, responsiveness, reliability, and empathy. When looking at the results, it cannot be said Memorial and Medicana Hospitals have significant differences concerning priorities. However, still, Medicana Hospital is better than Memorial with a little difference.

Table 2: AHP results

\section{Limitations}

\begin{tabular}{lrr}
\hline Alternative & \multicolumn{1}{c}{ Weight } & \multicolumn{2}{c}{ Ranking } \\
\hline Hospital A & 0.439 & 1 \\
Hospital B & 0.272 & 3 \\
Hospital C & 0.289 & 2 \\
\hline
\end{tabular}

In this study, it was challenging to find a patient who knows three hospitals' service quality. Because of this issue, just 42 patients were attended in the survey. These data were not adequate. Furthermore, the data collection method was also tricky. Some sub-criteria have the same meaning in terms of patients. These questions can be removed for further suggestions.

\section{Conclusions}

This study constructed the analytical hierarchy process (AHP) to evaluate the hospital service quality for kidney transplantation in Istanbul. Service quality parameters are determined in the light of four servqual dimensions, and significance levels are obtained using the analytic hierarchy process (AHP) in terms of patients and relatives. The results show that the best hospital for Kidney transplantation is selected Florence Nightingale Hospital in terms of service quality about four dimensions which are tangibles, responsiveness, reliability and empathy. For future research, the number of alternatives, criteria and attendees of the survey can be increased.

\section{Key References}

Aktas. A., Cebi, S., \& Temiz, I. (2015) A New Evaluation Model for Service Quality of Health Care Systems Based on AHP and Information axiom. Journal of Intelligent\& Fuzzy Systems, 28, 1009-1021.

Saaty TL. (1990) How to mark a decision: the analytic hierarchy process. European Journal of Operational Research,48, 9-26.

Url1, https://organ.saglik.gov.tr/Systems.aspx, Access Date: 20 October 2019.

Yucesan, M., \& Gul, M. (2020). Hospital service quality evaluation: an integrated model based on Pythagorean fuzzy AHP and fuzzy TOPSIS. Soft Computing, 24(5), 3237-3255. 